\title{
Evaluation of the antimicrobial performance of menthol and menthol-based deep eutectic solvents as potential future antibiotic
}

\author{
Nor Azrini Nadiha Azmi ${ }^{1}$, Amal Elgharbawy ${ }^{*}$,Hamzah Mohd Salleh ${ }^{1 *}$, and Adeeb Hayyan ${ }^{2}$ \\ ${ }^{1}$ International Institute for Halal Research and Training (INHART), International Islamic University Malaysia, P.O. Box 10, \\ 50278 Kuala Lumpur, Malaysia \\ ${ }^{2}$ Department of Chemical Engineering, Faculty of Engineering, Universiti Malaya, 50603 Kuala Lumpur, Malaysia
}

\begin{abstract}
Triggered by the strong antimicrobial activities of menthol and various fatty acids, eutectic mixtures based on the components are developed, producing new solvents that have possibilities to become a new antibiotic. This study aims to provide an insight into the antimicrobial activities of the new deep eutectic solvents (DESs) developed. Menthol-based DES combined with fatty acids, namely propionic acid, butanoic acid, hexanoic acid, octanoic acid, decanoic acid, and levulinic acid, were successfully obtained and their thermal profile was analyzed. The antimicrobial potential of DES systems was evaluated against both Gram positive and Gram negative bacteria. Owing to the activities of the start-up components, the results are considered promising, and this illustrates the potential of the newly obtained DESs as a new antimicrobial agent in various fields such as food, cosmetics as well as pharmaceutical.
\end{abstract}

\section{Introduction}

A novel solvent that fulfills the criteria of Green Chemistry has long become a dispute in the chemistry field. Abbott et al. [1] firstly pioneered deep eutectic solvent, a new type of solvents which interestingly appears to become alternatives to the conventional organic solvents. DESs defied most of the conventional solvents' characteristics. Different from the latter solvents, DESs exhibit excellent properties such as biodegradable, low costs, sustainable, non-volatile, nontoxic, and also easy and simple preparation [2].

DES is described as a mixture of two or more components, when at a certain molar ratio, significant reduction of the melting point is demonstrated, resulting in a liquid state at room temperature [3]; [4]. This combination is usually associated and characterized by a decreased freezing point than the individual compound [5]. This phenomenon appears as it is because of the formation of hydrogen bonding interactions between the compounds, namely hydrogen bond donor and another one as hydrogen bond acceptor [5].

The possibilities of the formation of DES are endless, accounting for possibly $10^{6}$ individual mixture. Thus, making DES flexible and tunable for many applications in various fields [6]. Due to the versatility, variety of DESs had been used in applications such as extraction media for bioactive natural component [7]; [8]; [9], electrochemical processes [10], and also molecular sensing [11]. Other than that, DES had been used in various research in the biomedical field in terms of enhancing the performance of biological materials and improving active pharmaceutical ingredients (APIs). Several studies recently have also focused on DES with antibacterial properties, which indicate the potential of DES as a wide-spectrum antiseptic agent for therapeutic and also preventive applications.

In this study, menthol was selected as a hydrogen bond acceptor, and various fatty acids act as hydrogen bond donor. Menthol is chosen for the activities it possessed. The biological properties of menthol include antibacterial, analgesic, anaesthetic, antifungal, and penetration-enhancing effects in addition to chemopreventive and immunomodulating actions [12]. Menthol had also emerged as both hydrogen bond donor and hydrogen bond acceptor in the formation of DESs $[5,13]$. Long-chain fatty acids were being used in this study as they exhibit antibacterial activity and are the key ingredients of antimicrobial food additives and some antibacterial herbs.

The aim was to reveal the potential of menthol and fatty acids as antimicrobial agents in DES form due to the possible synergistic effects among their counterparts. An insight into the antibacterial activity of the DESs formed from menthol, and different fatty acids with different chain size length are expected from this research.

\footnotetext{
* Corresponding author: hamzah@iium.edu.my
} 


\section{Experimental section}

\subsection{Preparation of DESs}

The DESs were prepared by mixing menthol and various fatty acids such as propionic acid (R\&M, $\geq 99 \%$ ), butanoic acid (R\&M, AR grade), hexanoic acid (Sigma Aldrich, $\geq 96 \%$ ), octanoic acid (Sigma Aldrich, $\geq 98 \%$ ), decanoic acid (R\&M, $\geq 99 \%$ ), levulinic acid (Nacalai Tesque, $\geq 97 \%$ ), palmitic acid (Sigma Aldrich, $\geq 98 \%$ ), and dodecanoic acid (R\&M, $\geq 99 \%)$ in the desired amounts, to obtain molar ratios of 1:1. The molar ratio is chosen as the reported procedure by [14]. For each mixture, the constituents were transferred into a completely sealed glass flask and heated to $70{ }^{\circ} \mathrm{C}$, for four hours without stirring for all the mixtures to ensure the formation of a homogenous, transparent liquid. The mixture was allowed to cool naturally to room temperature. For the mixtures which did not form a liquid, the process was considered concluded after $16 \mathrm{~h}$ [3]. Table 1 lists hydrogen bond acceptor and hydrogen bond donors used in the study.

Table 1. Hydrogen bond acceptor and hydrogen bond donor utilized in the study

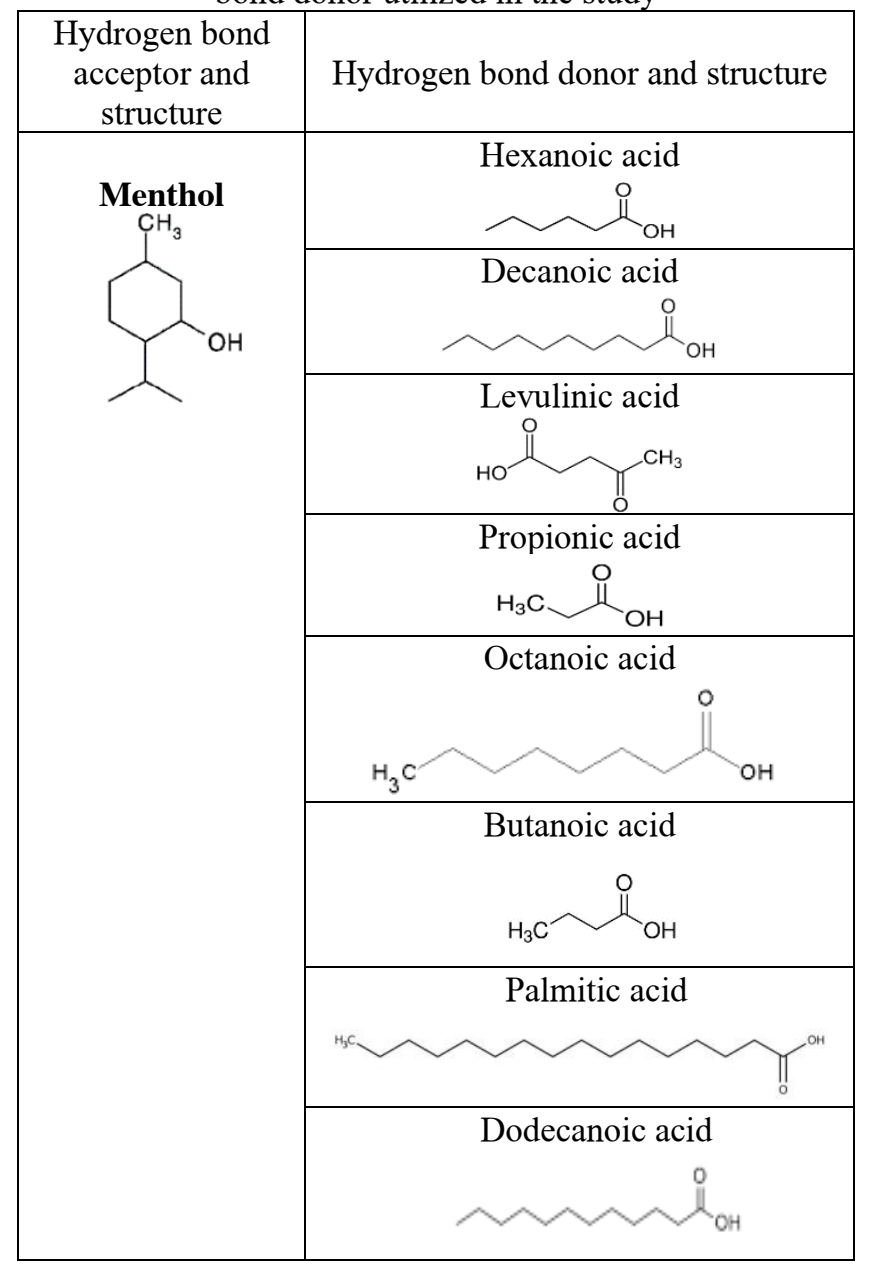

\subsection{Thermal analysis}

Differential scanning calorimetry (DSC) measurements were performed in aluminium cells at a heating rate of 10 ${ }^{\circ} \mathrm{C} /$ min (Mettler Toledo DSC 1, USA). Approximately 10-15 mg of DES samples were weighed into the aluminium liquid pan. Samples were scanned from -30 ${ }^{\circ} \mathrm{C}$ to $500{ }^{\circ} \mathrm{C}$. The experiments were performed under a nitrogen atmosphere $(50 \mathrm{ml} / \mathrm{min})$. The procedures followed [3].

\subsection{Assessment of antimicrobial activity}

Two Gram positive (Staphylococcus aureus ATCC 12600 and Bacillus subtilis ATCC11774) and one Gram negative bacteria (Escherichia coli ATCC 1129) were pre-cultured by transferring loopful of cells into $10 \mathrm{ml}$ of already autoclaved LB broth and allowed to incubate at $37{ }^{\circ} \mathrm{C}$ for $24 \mathrm{~h}$. The standard cells were spread on the plates by using a sterile cotton bud. For the disc diffusion assay, a sterile $6 \mathrm{~mm}$ diameter filter paper (Whatman No. 1) was soaked with different concentration DES solutions and allowed to equilibrate before placing on the seeded plates and allowed to stand before incubation. The plates were then incubated at $37{ }^{\circ} \mathrm{C}$ for $24 \mathrm{~h}$ before the diameters of zones of inhibition were then measured. These were repeated in three replicates for each of the tested organisms. Tetracycline at $5 \mathrm{mg} / \mathrm{ml}$ and $100 \%$ dimethyl sulfoxide (DMSO) were used as positive and negative controls, respectively [6];[15].

\section{Results and discussion}

\subsection{Preparation of DESs and visual aspect}

Eight samples of DESs were prepared using menthol as hydrogen bond donor and various fatty acids as hydrogen bond acceptor. The formation of the DESs, along with their designations as well as the visual aspect of the mixture are listed in Table 2.

Table 2. Components of the DESs, molar ratio used, and the visual aspects

\begin{tabular}{|c|c|c|c|c|}
\hline $\begin{array}{l}\text { Designa- } \\
\text { tion }\end{array}$ & $\begin{array}{c}\text { Compo- } \\
\text { nent } 1\end{array}$ & $\begin{array}{l}\text { Compo- } \\
\text { nent } 2\end{array}$ & $\begin{array}{c}\text { Molar } \\
\text { ratio }\end{array}$ & $\begin{array}{r}\text { Visual } \\
\text { aspect }\end{array}$ \\
\hline DES 1 & \multirow{8}{*}{ Menthol } & $\begin{array}{c}\text { Propionic } \\
\text { acid }\end{array}$ & \multirow{8}{*}{$1: 1$} & $\begin{array}{c}\text { Transparent } \\
\text { liquid }\end{array}$ \\
\hline DES 2 & & $\begin{array}{c}\text { Butanoic } \\
\text { acid }\end{array}$ & & $\begin{array}{c}\text { Transparent } \\
\text { liquid }\end{array}$ \\
\hline DES 3 & & $\begin{array}{c}\text { Hexanoic } \\
\text { acid }\end{array}$ & & $\begin{array}{c}\text { Transparent } \\
\text { liquid }\end{array}$ \\
\hline DES 4 & & $\begin{array}{c}\text { Octanoic } \\
\text { acid }\end{array}$ & & $\begin{array}{c}\text { Transparent } \\
\text { liquid }\end{array}$ \\
\hline DES 5 & & $\begin{array}{c}\text { Decanoic } \\
\text { acid }\end{array}$ & & $\begin{array}{c}\text { Transparent } \\
\text { liquid }\end{array}$ \\
\hline DES 6 & & $\begin{array}{c}\text { Levulinic } \\
\text { acid }\end{array}$ & & $\begin{array}{c}\text { Transparent } \\
\text { liquid }\end{array}$ \\
\hline DES 7 & & $\begin{array}{l}\text { Palmitic } \\
\text { acid }\end{array}$ & & \begin{tabular}{|c|} 
White, \\
Solid
\end{tabular} \\
\hline DES 8 & & $\begin{array}{c}\text { Dodecanoic } \\
\text { acid }\end{array}$ & & $\begin{array}{l}\text { White, } \\
\text { Solid }\end{array}$ \\
\hline
\end{tabular}


During the preparation process, throughout heating, the mixtures of menthol with all fatty acids gradually obtained the liquid aspect. However, upon cooling, only DES 1,2,3,4,5 and 6 retain as liquid such as illustrated in Figure 1. DES 7 and DES 8 were discarded from further characterization as both of the compounds are not successfully mixed and the products after cooling were in white solid form. The reason DES 7 and DES 8 are in solid phase after mixing and heating is most probably because the amount of menthol was not enough to build hydrogen bonding with the palmitic acid and dodecanoic acid. This results in a saturation of acid in the mixture and no further decrease in freezing point was achieved. The high concentration of hydrogen bond donor compared to hydrogen bond acceptor makes the mixture heterogeneous and even after a long time of shaking under high temperature, upon cooling, the mixture still becomes solid. This can also be seen in a study conducted by Hayyan et al. [16] that confront the same situation when the amount of glucose as hydrogen bond donor exceeds the amount of choline chloride which acts as hydrogen bond acceptor.

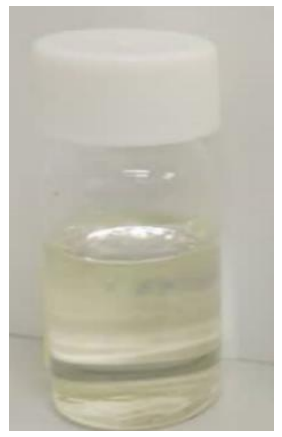

Figure 1. Successful DES 2 obtained when menthol and butanoic acid are combined with 1:1 molar ratio.

\subsection{Thermal analysis}

Differential scanning calorimetry is one of the most used methods for thermal analysis, measuring the temperature and energy associated with a range of thermal events, including melting, crystallization, and glass transitions. Many studies have been using this method to analyze the thermal events happening in the DESs. The melting point of the menthol and their eutectic mixtures are also presented in Table 3.

Table 3. Melting temperatures of menthol and DES obtained in the study

\begin{tabular}{|c|c|}
\hline Component/Mixture & $\mathbf{T}_{\mathbf{m}}\left({ }^{\circ} \mathbf{C}\right)$ \\
\hline Menthol & 38.00 \\
\hline DES 1 & 41.34 \\
\hline DES 2 & 195.89 \\
\hline DES 3 & 158.68 \\
\hline DES 4 & 160.07 \\
\hline DES 5 & 95.95 \\
\hline DES 6 & 59.59 \\
\hline
\end{tabular}

From Table 3, D,L-menthol shows melting point at $38^{\circ} \mathrm{C}$. (Alhadid et al., [17] decribed L-menthol had low value of melting enthalpy, thus making L-menthol a good candidate for designing deep eutectic systems. It can be seen clearly that in all cases, the melting temperature of the mixture is different than those of the pure starting components, which confirms that these DES are supramolecular complexes in the liquid state over a wide temperature range. Consequently, less pure compounds will exhibit a broadened melting peak that begins at a lower temperature than a pure compound as shown in Figure 2 exhibiting the thermal profile of DES 4. In all the DESs, a depression of the melting point occurs. Figure 2 shows the DSG thermogram for DES 4, where all the peaks are endothermic suggesting fusion process is occurring. Endothermic process is a thermal event of a material where energy is absorbed by the material which appears to occur in this case. This is similar to all DSC analysis of the DES in this study.

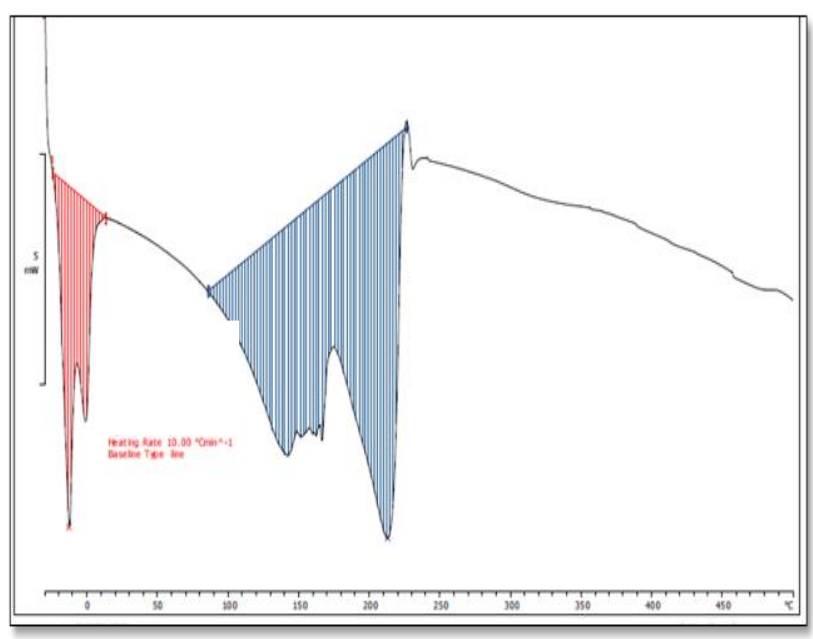

Figure 2. The thermal profile of DES 4 (Menthol: Octanoic acid with 1 to 1 ratio).

\subsection{Antimicrobial properties evaluation}

The antimicrobial potential of the various DES formulations was evaluated using disk diffusion assay, which was carried out using different selected microbial strains. From Table 2, it can be seen that all the DESs exhibit antimicrobial properties against all microbes tested. The results for Gram positive bacteria, B. subtilis and $S$. aureus is supported by a similar study [6], which shows good inhibition of the DESs to the tested microbes. The largest inhibition zone for B. subtilis is obtained when using DES 2, and the smallest is with DES 4. DES 2 also showed the largest inhibition zone for $S$. aureus, while DES 1 has the smallest inhibition zone. The results are comparable to the study by (Huang et al. [18], which stated that short and medium-chain fatty acids possessed antibacterial activity. The reason for this is thought to be attributed to the cell wall of Gram positive bacteria which readily absorbs fatty acids allowing their passage into the inner membrane, thus interact with intracellular sites critical for antibacterial activity [19]. However, our results for Gram negative 
bacteria, E. coli is very different from their study. In this study, DES 3 showed the largest inhibition zone, while the smallest was exhibited by DES 4. Piran et al. [19] stated that Gram negative bacteria are usually resistant to the antibacterial activity of fatty acids because of more complex membrane structure. Desbois and Smith [20] reported that the presence of lipopolysaccharides on the cell wall prevents the fatty acids from reaching cell membrane and exerting its effect. However, our results showed different trends and this could be due to the presence of menthol. Menthol possessed strong antibacterial activity towards Gram negative bacteria [21]. Figure 3 (a) and (b) show the inhibition zones of the DES on microbes tested.

Table 4. Inhibition measurements (diameter (mm) \pm SD) for the various DES formulations. Results are presented by formulation for each microbial strain tested.

Tetracycline is positive control and DMSO is the negative control.

\begin{tabular}{|c|c|c|c|}
\hline DESs & B. subtilis & S. aureus & E. coli \\
\hline DES 1 & $10.33 \pm 0.57$ & $6.33 \pm 0.94$ & $6.00 \pm 0.47$ \\
\hline DES 2 & $14.67 \pm 0.47$ & $11.67 \pm 0.82$ & $4.33 \pm 0.57$ \\
\hline DES 3 & $12.67 \pm 1.15$ & $8.67 \pm 0.57$ & $8.67 \pm 1.52$ \\
\hline DES 4 & $6.33 \pm 1.52$ & $8.67 \pm 0.58$ & $1.33 \pm 0.57$ \\
\hline DES 5 & $8.67 \pm 1.52$ & $7.67 \pm 0.57$ & $2.33 \pm 0.82$ \\
\hline DES 6 & $10.33 \pm 0.47$ & $7.00 \pm 1.00$ & $8.00 \pm 1.15$ \\
\hline DMSO & $0.00 \pm 0.00$ & $0.00 \pm 0.00$ & $0.00 \pm 0.00$ \\
\hline Tetracycline & $35.67 \pm 0.33$ & $38.50 \pm 0.41$ & $24.33 \pm 0.94$ \\
\hline
\end{tabular}
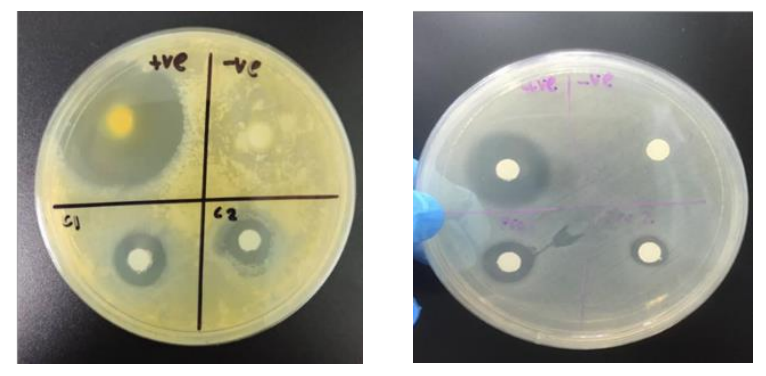

Figure 3. (a) shows the inhibition zone of DES 5 on $B$. subtilis and (b) shows the inhibition zone of DES 3 on $E$. coli.

\section{Conclusion}

Due to the renowned antimicrobial properties of fatty acids and menthol, this study presented new green solvents based on eutectic mixtures. This study provides an insight into the antimicrobial activity of menthol based DESs. Antimicrobial activity of different DESs was assessed against three types of microbes. From the results obtained, one of the promising DES was DES 2 (menthol: butanoic acid at 1:1 molar ratio) which had the largest inhibition zone against both Gram positive bacteria tested. DES 3 (menthol: hexanoic acid at 1:1 molar ratio) possessed the highest antimicrobial activity against E. coli which is a Gram negative bacteria. A more thorough study on antimicrobial activity of DESs should be carried out ton a wider array of microbes. These DESs might be one of the components to produce antimicrobial agents in food, cosmetics, or even pharmaceutical area as it consists of natural constituents.

\section{Acknowledgement}

This research was funded by the Fundamental Research Grant Scheme, MoHE-Malaysia [FRGS19-027-0635] (Hamzah Mohd Salleh), and Research Management Centre, IIUM [RMCG20-021-0021] (Amal A. M. Elgharbawy).

\section{References}

1. Abbott, A.P.; Capper, G.; Davies, D.L.; Rasheed, R.K.; Tambyrajah, V. Chem. Commun. 70-71, (2003).

2. Dai, Y.; Witkamp, G.; Verpoorte, R.; Hae, Y. FOOD Chem. 187, 14-19, (2015).

3. Aroso, I.M.; Paiva, A.; Reis, R.L.; Duarte, A.R.C. J. Mol. Liq., 241, 654-661, (2017).

4. Hayyan, A.; Mjalli, F.S.; AlNashef, I.M.; AlWahaibi, T.; Al-Wahaibi, Y.M.; Hashim, M.A. Thermochim. Acta, 541, 70-75, (2012).

5. Ribeiro, B.D.; Florindo, C.; Coelho, M.A.Z.; Marrucho, I.M. (2015).

6. Silva, J.M.; Silva, E.; Reis, R.L.; Duarte, A.R.C. Sustain. Chem. Pharm. 14, 100192, (2019).

7. Ahmad, I.; Pertiwi, A.S.; Kembaren, Y.H.; Rahman, A.; Mun'im, A. J. Appl. Pharm. Sci., 8, 138-143, (2018).

8. Dai, Y.; Witkamp, G.J.; Verpoorte, R.; Choi, Y.H. Anal. Chem., 85, 6272-6278, (2013).

9. Saravana, P.S.; Ho, T.C.; Chae, S.J.; Cho, Y.J.; Park, J.S.; Lee, H.J.; Chun, B.S. Carbohydr. Polym., 195, 622-630, (2018).

10. Baby, J.N.; Sriram, B.; Wang, S.F.; George, M. ACS Sustain. Chem. Eng., 8, 1479-1486, (2020).

11. Krishnan, S.K.; Chipatecua Godoy, Y. ACS Omega, 5, 1384-1393, (2020).

12. A. Farco, J.; Grundmann, O. Mini Rev. Med. Chem., 13, 124-131, (2012).

13. Pereira, C. V.; Silva, J.M.; Rodrigues, L.; Reis, R.L.; Paiva, A.; Duarte, A.R.C.; Matias, A. Sci. Rep., 9, 1-11, (2019).

14. Tang, W.; Dai, Y.; Row, K.H. Anal. Bioanal. Chem., 410, 7325-7336, (2018).

15. Hayyan, M.; Hashim, M.A.; Al-Saadi, M.A.; Hayyan, A.; AlNashef, I.M.; Mirghani, M.E.S. Chemosphere, 93, 455-459, (2013).

16. Hayyan, A.; Mjalli, F.S.; AlNashef, I.M.; AlWahaibi, Y.M.; Al-Wahaibi, T.; Hashim, M.A. J. Mol. Liq., 178, 137-141, (2013).

17. Alhadid, A.; Mokrushina, L.; Minceva, M. Molecules, 25, 1-11, (2020).

18. Huang, C.B.; Alimova, Y.; Myers, T.M.; Ebersole, J.L. Arch. Oral Biol., 56, 650-654, (2011).

19. Piran, P.; Kafil, H.S.; Ghanbarzadeh, S.; Safdari, R.; Hamishehkar, H. Adv. Pharm. Bull., 7, 261268, (2017). 
20. Desbois, A.P.; Smith, V.J. Appl. Microbiol. Biotechnol., 85, 1629-1642, (2010).

21. Pl'uchtová, M.; Gervasi, T.; Benameur, Q.;

Pellizzeri, V.; Grul'ová, D.; Campone, L.; Sedlák, V.; Cicero, N. Nat. Prod. Commun. 13, 1051-1054(2018). 